\title{
Echocardiographic features of impaired ventricular function in diabetes mellitus
}

\author{
LEONARD M SHAPIRO* \\ From the Department of Cardiology, Dudley Road Hospital, Birmingham
}

SUMMARY In order to study left ventricular diastolic function in diabetes mellitus, simultaneous echo- and phonocardiograms were recorded in 142 diabetics (free from heart disease), 20 normal subjects, and 16 patients with coronary artery disease. The resultant traces were digitised, and left ventricular relaxation and the rate and duration of cavity dimension increase and wall thinning were determined. Diastolic variables of left ventricular function were normal in 12 young diabetics with no complications. Significantly delayed mitral valve opening relative to minimum dimension and aortic valve closure was found in all other groups of diabetics. Forty-four diabetics with severe microvascular complications had significantly reduced peak rate and prolonged duration of wall thinning and dimension increase. The abnormalities were unlike those found in subjects with coronary artery disease.

The extent of microvascular complications was significantly correlated to most variables of diastolic function. This relation was maintained in 31 diabetics with significant cavity dimension increase during isovolumic relaxation (incoordinate relaxation). In 42 juvenile onset patients there was good correlation between the duration of diabetes and most variables of diastolic function.

These studies show that the primary cardiac abnormality in diabetic micro-angiography is a prolonged duration and reduced rate of posterior wall thinning with impaired left ventricular dimension increase, reflecting abnormal myocardial properties.

Impaired left ventricular function may frequently be detected in asymptomatic diabetics. ${ }^{1}$ It is related to the presence and extent of diabetic microvascular complications and the duration of diabetes, and is presumably the result of specific diabetic myocardial involvement. ${ }^{2}$ Although systolic time intervals are abnormal in some diabetics, ${ }^{1-5}$ they have a complex underlying mechanism and are more frequently abnormal in diabetics with associated disorders such as hypertension, coronary artery disease, and heart failure. ${ }^{1}$ The studies of Sanderson et al. ${ }^{6}$ and Shapiro et al. ${ }^{125}$ suggest that impairment of some aspects of diastolic function is common and may be the primary abnormality in diabetes; the purpose of the present paper is to extend previous studies of diastolic left ventricular function by detailed examination of relaxation, cavity filling, and wall thinning using computerised interpretation of manually digitised echocardiograms.

\footnotetext{
^Present address: Royal Postgraduate Medical School, Hammersmith Hospital, Du Cane Road, London W12 0HS.

Accepted for publication 8 October 1981
}

\section{Patients and methods}

Patients and control subjects have previously been described in detail. ${ }^{2}$ From 473 diabetics, aged 16 to 60 years, 185 were selected as free from clinical heart disease, hypertension (diastolic blood pressure above $100 \mathrm{mmHg}$ ), and conditions known to influence left ventricular function. Of these, 142 had echocardiograms which were suitable for the computerised analysis (79 men and 63 women, mean age $41 \pm 9$ years); 42 of these were insulin-dependent diabetics who developed the disease before the age of 20 in whom the clinical presentation of diabetes was assumed to represent its onset. These 42 patients were used to determine relations to the duration of diabetes (mean duration of diabetes $9 \pm 8$ years, range 0 to 25 years).

The 142 diabetics were subdivided into the following groups:

(i) Diabetics with no complications $(\mathrm{n}=39)$.

(ii) Diabetics with mild microvascular complications, mild background retinopathy, and/or mild proteinuria $(n=47)$. 
(iii) Diabetics with severe microvascular complications, heavy proteinuria, and/or proliferative retinopathy $(n=44)$.

(iv) Recently diagnosed (within three years) young insulin-dependent diabetics $(n=12)$.

The 142 diabetics were graded according to the presence and extent of complications and an index of microvascular complications was constructed by summation of the individual scores for each complication subgroup (Table 1) which allowed for a scale from zero (with no complications, as in groups (i) and (iv)) to seven (when all were present and severe as in some patients in group (iii)).

Table 1 Scheme for grading microvascular complications

\begin{tabular}{ll}
\hline Code & $\begin{array}{l}\text { Retinopathy } \\
\text { None } \\
\text { Mild background: less than } 10 \text { red dots per eye } \\
1\end{array}$ \\
2 & $\begin{array}{l}\text { Severe background: greater than } 10 \text { red dots per } \\
\text { eye }\end{array}$ \\
3 & Proliferative \\
& $\begin{array}{l}\text { Proteinuria } \\
\text { None } \\
\text { Mild: one or two plus proteinuria } \\
1\end{array}$ \\
2 & $\begin{array}{l}\text { Severe: heavy proteinuria } \\
\text { Neuropathy } \\
\text { None } \\
\text { Mild: absent ankle jerks and vibration sense in } \\
\text { feet }\end{array}$ \\
1 & $\begin{array}{l}\text { Severe: further evidence of neuropathy } \\
\text { including autonomic neuropathy }\end{array}$ \\
\hline
\end{tabular}

Two groups were selected as controls:

(i) Twenty normal subjects, 10 men and 10 women (mean age $39 \pm 11$ years) from members of hospital staff, and patients undergoing investigation of atypical chest pain who had normal coronary and left ventricular angiograms.

(ii) Sixteen patients with typical angina of exertion (nine men and seven women, mean age $40 \pm 8$ years), from those undergoing investigation of chest pain. All had significant coronary atheroma on angiography and none was taking beta-adrenergic blocking agents.

Echocardiography with simultaneous electrocardiogram (standard lead II) and phonocardiogram to determine onset of high frequency component of the aortic heart sound $\left(A_{2}\right)$ was performed in the partial left lateral position with an SK20 ultrasonoscope and a Cambridge multichannel photographic recorder, paper speed $100 \mathrm{~mm} / \mathrm{s}$. A left ventricular echocardiogram at the level of the tips of the mitral valve showing clear continuous echoes from both the septum and posterior wall endo- and epicardium was used for further analysis (Fig. 1).

Echocardiographs were digitised as previously described by Gibson and Brown, ${ }^{7}$ using a Summa-

\section{Fig. 1 Normal left ventricular echocardiogram with} simultaneous phonocardiogram (PCG), electrocardiogram $(E C G)$, and apexcardiogram ( $A C G)$. MVO, mitral valve opening; IVS, interventricular septum; $P W$, posterior wall.

graphics digitiser and a Prime 300 computer system. From the records the following measurements were made (Fig. 2).

(1) End-diastolic ( $R$ wave electrocardiogram) posterior wall thickness $(\mathrm{cm})$.

(2) Peak rate of change of posterior wall thickness in early diastole $8(\mathrm{~cm} / \mathrm{s})$.

(3) Interval from maximum posterior wall thick-ō ness to its decline to $20 \%$ of peak value, arbitrarily defined as duration of rapid thinning ${ }^{8}$ (ms).

(4) Peak rate of increase in left ventricular dimen-sion during early diastole $(\mathrm{cm} / \mathrm{s})$.

(5) Duration of increase in left ventricular dimension in early diastole, arbitrarily defined as the time? from minimal left ventricular dimension to time of decline in rate to $20 \%$ of peak value ${ }^{7}(\mathrm{~ms})$.

(6) Time intervals (in ms) from minimal left ventricular dimension to the onset of mitral valve opening윽 (measured at cusp separation); and from the first low frequency vibrations of $A_{2}$ to mitral valve opening (isovolumic relaxation time).

(7) Change in left ventricular dimension during isovolumic relaxation, expressed as percentage of total 0 dimension change during the cardiac cycle.

STATISTICAL METHODS

Values are quoted as mean \pm one standard deviation. Student's t test was used to test differences between $?$ variables. The degree of relation between left ven-? tricular function and microvascular complications? index and duration of diabetes were estimated with Kendal's rank order correlation coefficient $(\tau)$ and $\mathbb{\mathbb { Q }}$ Pearson's correlation coefficient (r), respectively. 


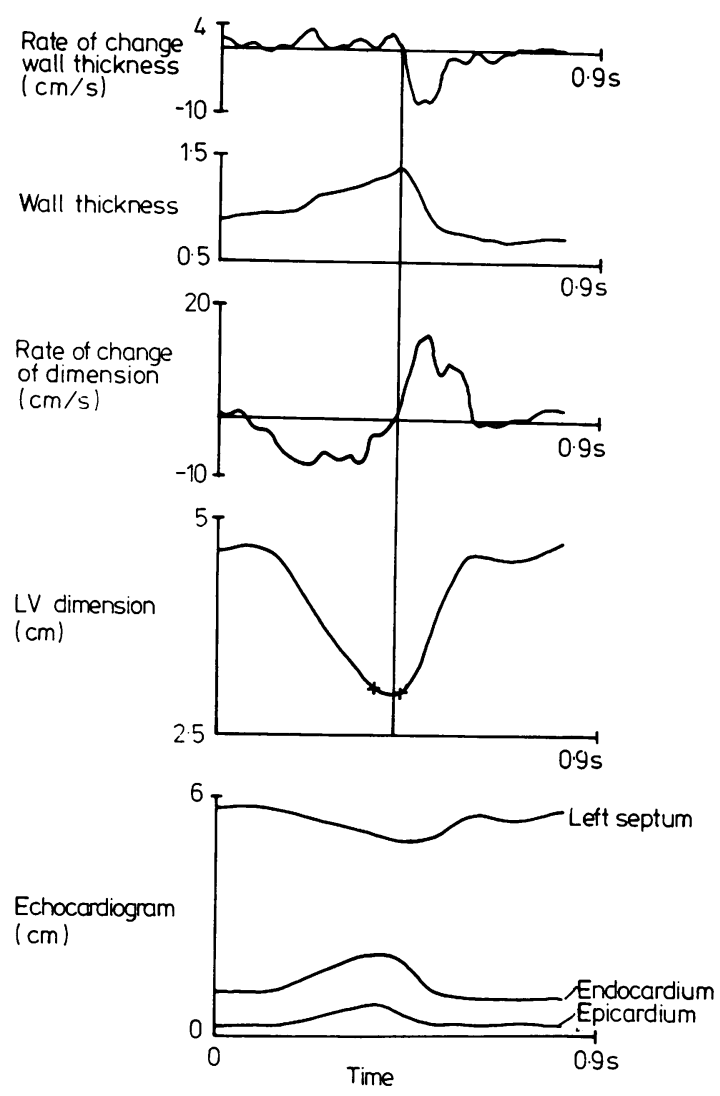

Fig. 2 Computer output of normal left ventricular (LV) echocardiogram showing from the lowest panel upwards, the digitised data, a continuous plot of left ventricular dimension and its rate of change, and a continuous plot of posterior wall thickness and its rate of change. The two crosses on the dimension trace represent the timing of $A_{2}$ and mitral valve opening and the vertical line represents minimal cavity dimension.

\section{Results}

\section{(1) COMPARISON OF CONTROL SUBJECTS AND} DIABETICS (Table 2)

All diabetics had normal wall thicknesses. Young diabetics with no complications had normal function. The other groups of diabetics had significantly delayed mitral valve opening relative to $A_{2}(p<0.05$ to $\mathrm{p}<0.001)$ and minimum dimension $(\mathrm{p}<0.001)$. The duration of posterior wall thinning $(p<0.001)$ and rate of dimension increase $(p<0.001)$ were significantly abnormal in patients with mild complications, while those with severe complications had abnormalities in all variables of diastolic function measured compared with normal subjects ( $p<0.001$ ) (Fig. 2 and 3 ).

There was a wide scatter of values for the dimension change before mitral valve opening, the mean for

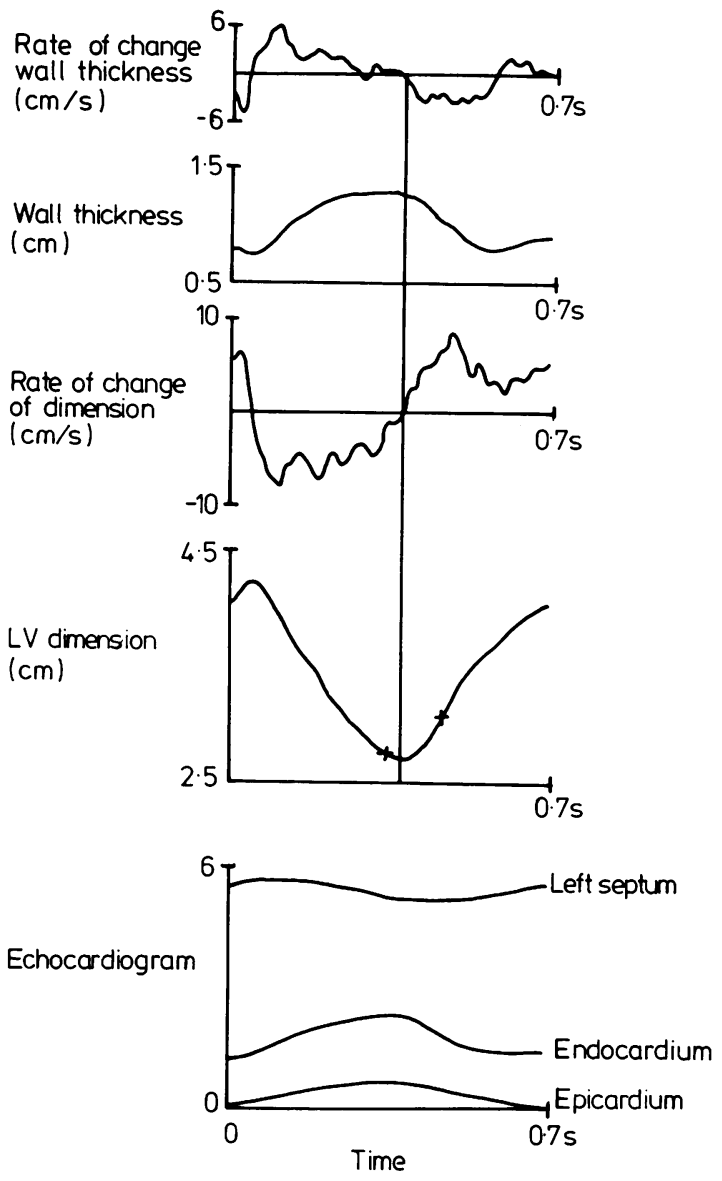

Fig. 3 Computer output of diabetic with proliferative retinopathy and proteinuria showing delayed mitral valve opening, slow and prolonged filling, and wall thinning.

diabetics with no, mild, and severe complications being significantly different from normal $(p<0.05$, $\mathrm{p}<0.01$, and $\mathrm{p}<0.001$, respectively). One hundred and eleven diabetics showed less than a $15 \%$ change (3 SD from normal) (mean $4 \pm 7 \%$ ) and the 31 with more than this contributed the majority of the mean change $(26 \pm 12 \%)$. These latter subjects with significant increase in cavity dimension during isovolumic relaxation (incoordinate relaxation) were distributed throughout the diabetic subgroups.

In subjects with coronary artery disease, though the peak rate of dimension increase was moderately reduced from normal $(p<0.05)$, the major abnormality was delay in mitral valve opening relative to minimum dimension $(p<0.001$ vs normal, $p<0.01$ to $p<0.001$ vs all diabetic subgroups) and the associated dimension change $(p<0.001$ vs normal, $p<0.01$ vs all 
Table 2 Left ventricular function in control subjects and diabetics

\begin{tabular}{|c|c|c|c|c|c|c|c|c|c|}
\hline & \multirow[t]{2}{*}{ No. } & \multirow{2}{*}{$\begin{array}{l}\text { Posterior } \\
\text { wall end- } \\
\text { diastolic } \\
\text { thickness } \\
(\mathrm{cm})\end{array}$} & \multicolumn{2}{|c|}{$\begin{array}{l}\text { Peak diastolic rate of } \\
\text { change of }\end{array}$} & \multicolumn{2}{|l|}{ Duration of } & \multicolumn{2}{|c|}{ Time intervals } & \multirow{2}{*}{$\begin{array}{l}\text { Dimension } \\
\text { change during } \\
\text { isovolumic } \\
\text { relaxation } \\
\text { as } \% \text { total }\end{array}$} \\
\hline & & & $\begin{array}{l}\text { Wall } \\
\text { thickness } \\
(\mathrm{cm} / \mathrm{s})\end{array}$ & $\begin{array}{l}\text { Dimension } \\
(\mathrm{cm} / \mathrm{s})\end{array}$ & $\begin{array}{l}\text { Rapid } \\
\text { thinning } \\
(m s)\end{array}$ & $\begin{array}{l}\text { Early } \\
\text { diastolic } \\
\text { dimension } \\
\text { increase } \\
\text { (ms) }\end{array}$ & $\begin{array}{l}\text { Minimum } \\
\text { dimension } \\
\text { to } M V O \\
(\mathrm{~ms})\end{array}$ & $\begin{array}{l}\mathrm{A}_{2} \text { to } \\
M V O \\
(m s)\end{array}$ & \\
\hline $\begin{array}{l}\text { Normal } \\
\text { Coronary artery disease } \\
\text { Young diabetics } \\
\text { No complications } \\
\text { Mild complications } \\
\text { Severe complications }\end{array}$ & $\begin{array}{l}20 \\
16 \\
12 \\
39 \\
47 \\
44\end{array}$ & $\begin{array}{l}0.8 \pm 0.2 \\
0.9 \pm 0.2 \\
0.8 \pm 0.2 \\
0.8 \pm 0.2 \\
0.9 \pm 0.2 \\
0.9 \pm 0.2\end{array}$ & $\begin{array}{l}11 \pm 2 \\
10 \pm 4 \\
11 \pm 1 \\
10 \pm 4 \\
9 \pm 4 \\
7 \pm 4+96\end{array}$ & $\begin{array}{l}18 \pm 4 \\
14 \pm 5 \| \\
18 \pm 2 \\
15 \pm 5 \| \\
13 \pm 5+ \\
10 \pm 5+56\end{array}$ & $\begin{array}{l}105 \pm 24 \\
115 \pm 36 \\
95 \pm 20 \\
120 \pm 41 \\
140 \pm 43+ \\
159 \pm 60+55\end{array}$ & $\begin{array}{l}166 \pm 40 \\
175 \pm 47 \\
153 \pm 37 \\
175 \pm 45 \\
187 \pm 47 \\
226 \pm 64+56\end{array}$ & $\begin{array}{l}14 \pm 3 \\
74 \pm 15 t \\
12 \pm 36 t+ \\
32 \pm 29+\ddagger \\
44 \pm 28+t+ \\
58 \pm 23+55\end{array}$ & $\begin{array}{l}60 \pm 12 \\
73 \pm 25 \\
56 \pm 7 \\
72 \pm 215 \\
75 \pm 225 \\
89 \pm 194\end{array}$ & $\begin{array}{c}3 \pm 4 \\
19 \pm 10+ \\
2 \pm 3+1 \\
8 \pm 10 \| 5 \\
10 \pm 8555 \\
11 \pm 9+85\end{array}$ \\
\hline
\end{tabular}

\pm , one SD; MVO, mitral valve opening.

Difference from normal: $\nmid \mathrm{p}<0.001 ; \ddagger \mathrm{p}<0.005 ; \uparrow \mathrm{p}<0.01 ; \| \mathrm{p}<0.05$.

Difference between subjects with coronary artery disease and diabetes: $t p p<0.001 ; \$ \$ p<0.01$.

Table 3 Relations of left ventricular function to microvascular complications index (Kendal's rank order correlation)

\begin{tabular}{|c|c|c|c|c|c|c|c|c|}
\hline & \multirow[t]{2}{*}{ No. } & \multicolumn{2}{|c|}{$\begin{array}{l}\text { Peak diastolic rate of } \\
\text { change of }\end{array}$} & \multicolumn{2}{|c|}{ Duration of } & \multicolumn{2}{|c|}{ Time intervals } & \multirow{2}{*}{$\begin{array}{l}\text { Dimension } \\
\text { change } \\
\text { during } \\
\text { isovolumic } \\
\text { relaxation } \\
\text { as } \% \text { total }\end{array}$} \\
\hline & & $\begin{array}{l}\text { Wall } \\
\text { thickness }\end{array}$ & Dimension & $\begin{array}{l}\text { Rapid } \\
\text { thinning }\end{array}$ & $\begin{array}{l}\text { Early } \\
\text { diastolic } \\
\text { dimension } \\
\text { increase }\end{array}$ & $\begin{array}{l}\text { Minimum } \\
\text { dimension } \\
\text { to MVO }\end{array}$ & $\begin{array}{l}A_{2} \text { to } \\
M V O\end{array}$ & \\
\hline \multirow{2}{*}{$\begin{array}{l}\text { All diabetics } \\
\text { Diabetics with a dimension } \\
\text { change greater than } 3 \text { SD } \\
\text { from normal }(15 \%)\end{array}$} & 142 & $-0.2 \dagger$ & $-0.17 \ddagger$ & $0 \cdot 12$ & $0.2 \dagger$ & $0.24 t$ & $0.23 t$ & 0.069 \\
\hline & 31 & -0.38 & -0.12 & $0 \cdot 16 \pi$ & $0 \cdot 17 \pi$ & $0.21 \ddagger$ & 0.20 市 & 0.099 \\
\hline
\end{tabular}

Significances: $\nmid p<0.001 ; \ddagger p<0.005 ; \uparrow p<0.01 ;$ १NS.

diabetic subgroups). There was, however, only a small prolongation of the isovolumic relaxation time because $A_{2}$ and minimum dimension were almost synchronous, compared with the normal interval of 30 to $50 \mathrm{~ms}$. In most diabetics this interval was normal, and delayed mitral valve opening was associated with prolonged isovolumic relaxation, and little dimension change.

\section{(2) RELATIONS TO CLINICAL FEATURES OF} DIABETICS

In the total group $(n=142)$ there was a close correlation between function and the microvascular complication index. A similar relation was maintained within the subgroup of diabetics with more than $15 \%$ dimension change $(n=31)$ for peak rate of wall thinning $(p<0.01)$, isovolumic relaxation time $(p<0.005)$, and interval from minimum dimension to mitral valve opening $(p<0.005)$ (Table 3$)$.

In 42 insulin-dependent diabetics diagnosed before the age of 20 years the duration of diabetes was related to peak rate of wall thinning $(p<0.01)$, duration of dimension increase $(p<0.01)$, isovolumic relaxation time $(p<0.001)$, and the interval from minimum dimension to mitral valve opening $(p<0.001)$ (Table 4).

\section{Discussion}

Computerised interpretation of the M-mode echocardiogram is an excellent way of studying left ventricular diastolic function because of an unequivocal identification of the epi- and endocardial surfaces and mitral valve opening. ${ }^{79}$

The timing of aortic valve closure represented by $\mathrm{A}_{2}$ was normal in healthy subjects and most diabetics. Mitral valve opening was significantly delayed relative to minimum dimension in most diabetics, and this was the result of prolonged isovolumic relaxation. Both were strongly correlated with the microvascular complications index and duration of diabetes ${ }^{16}$ and, as expected, only young diabetics were normal. Such 0

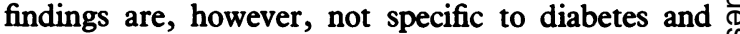
have been described in other cardiac disorders, ${ }^{7-11}$ ? and are the result of disturbed ventricular relaxation.

In subjects with coronary artery disease and in diabetics with incoordinate relaxation, mitral valve opening was also delayed relative to minimum dimen- $\frac{\alpha}{\alpha}$ sion, but isovolumic relaxation time was only slightly 
Table 4 Relations of left ventricular function to duration of diabetes (Pearson's correlation coefficient)

\begin{tabular}{|c|c|c|c|c|c|c|c|c|}
\hline & \multirow[t]{2}{*}{ No. } & \multicolumn{2}{|c|}{$\begin{array}{l}\text { Peak diastolic rate of } \\
\text { change of }\end{array}$} & \multicolumn{2}{|c|}{ Duration of } & \multicolumn{2}{|c|}{ Time intervals } & \multirow{2}{*}{$\begin{array}{l}\text { Dimension } \\
\text { change } \\
\text { during } \\
\text { isovolumic } \\
\text { relaxation } \\
\text { as } \% \text { total }\end{array}$} \\
\hline & & $\begin{array}{l}\text { Wall } \\
\text { thickness }\end{array}$ & Dimension & $\begin{array}{l}\text { Rapid } \\
\text { thinning }\end{array}$ & $\begin{array}{l}\text { Early } \\
\text { diastolic } \\
\text { dimension } \\
\text { increase }\end{array}$ & $\begin{array}{l}\text { Minimum } \\
\text { dimension } \\
\text { to MVO }\end{array}$ & $\begin{array}{l}A_{2} \text { to } \\
M V O\end{array}$ & \\
\hline $\begin{array}{l}\text { Juvenle onset insuln- } \\
\text { dependent diabetes }\end{array}$ & 42 & -0.45 & -0.39 & 0.29 & $0.44 \$$ & $0.66 t$ & $0.61 t$ & 0.249 \\
\hline
\end{tabular}

Significances: $\nmid p<0.001 ;$ $p<0.01 ;$ १NS.

prolonged. In this situation it has been shown that though the timing of $A_{2}$ is normal, minimum dimension occurs relatively early because of incoordinate systolic wall motion, accompanied by increase in cavity dimension before mitral valve opening, because of incoordinate relaxation. ${ }^{8-10}$ Seventy-eight per cent of diabetics and all normal controls showed no significant change of dimension during isovolumic relaxation. There was, however, a wide range of values for dimension change during isovolumic relaxation and 15\% (3 SD from normal) arbitrarily defined incoordinate relaxation. This is found in coronary artery disease and other left ventricular diseases and is usually explained by segmental abnormalities of relaxation. ${ }^{9}$ Incoordinate relaxation was found in 31 diabetics but there was no trend towards greater dimension change with increasing severity of microvascular complications.

While the incoordination may be the result of microvascular disease with patchy fibrosis impairing regional myocardial function, it is more likely that the cause is asymptomatic but significant coronary artery stenosis, especially as similar abnormalities have been noted in diabetics with angina. ${ }^{1}$

In diabetics with severe complications delayed mitral valve opening was accompanied by prolonged duration and reduced rate of dimension increase, and these abnormalities were closely correlated with the extent of microvascular complications. In diabetics with severe complications the pattern of increase in cavity dimension was similar to that described in mitral $^{7}$ and aortic valve stenosis, and hypertrophic cardiomyopathy and severe hypertension. ${ }^{11}$ The abnormal filling in mitral stenosis is caused by inflow-tract obstruction, but in aortic stenosis, hypertrophic cardiomyopathy, and hypertension the abnormal filling and relaxation is caused by the altered properties of the hypertrophied ventricle. ${ }^{811}$ Similarly, in diabetics the pattern of slow and prolonged increase in dimension was not the result of haemodynamic factors, and was totally unlike the asynchronous abnormalities with essentially normal filling in coronary artery disease.

In diabetics wall thickness was normal. In those subjects with severe complications the peak rate of wall thinning was reduced and prolonged in a manner similar to dimension increase; these abnormalities, similar to those found in the hypertrophied myocardium, ${ }^{8}$ were correlated to duration of diabetes and microvascular complications. In coronary artery disease rapid wall thinning is normal. ${ }^{8}$ Within the subgroup of diabetics with incoordinate relaxation there was a wide range of rates and durations of thinning and increase in dimension, which could also be correlated with the clinical features of diabetes. Therefore, impairment of wall thinning and dimension increase must be the result of abnormal properties of myocardium, which are independent of, and can coexist with, segmental abnormalities of arterial supply.

Diabetics, especially those with severe microvascular complications, have small vessel involvement of the coronary microcirculation analogous to that in the retina and kidney. ${ }^{12-15}$ Capillary microaneurysms, basement membrane thickening, and endothelial proliferation have been described in necropsy and biopsy studies. These small vessel abnormalities ultimately induce diffuse myocardial ischaemia, with resultant extracellular fibrosis. Experimental evidence in dogs rendered diabetic with alloxan suggests that myocardial glycoprotein deposition can impair the left ventricular end-diastolic pressure/volume ratio. ${ }^{13}$ These pathological changes would disrupt the active processes which determine changes in myocardial properties that are responsible for relaxation and filling. ${ }^{16}$ This would readily explain the impaired wall thinning. The role of diffuse ischaemia is uncertain as myocardial cells have a normal structure ${ }^{13}$ but may well be important in impairing function.

"Heart failure" and "cardiomyopathy" have been attributed by some authors to diabetes in subjects with recently diagnosed or uncomplicated diabetes or an impaired glucose tolerance test. ${ }^{15}$ From this and previous studies, ${ }^{12}$ it is clear that there is a graded response in left ventricular function to the severity of diabetes; in general only subjects with severe microvascular complications had impaired wall thinning, and heart failure usually only occurred in diabetics with severe complications and was often associated with 
hypertension. ${ }^{1}$ It is, therefore, unlikely that specific diabetic heart disease is responsible for heart failure in subjects with mild diabetes who would not be expected to have coronary microangiopathy, though such patients do have impaired relaxation; this may well explain the increased mortality occurring after myocardial infarction.

The present echocardiographic study shows that in diabetes, though the myocardium is not hypertrophied it has similar properties to those found in myocardial hypertrophy with abnormal relaxation and wall thinning. This supports haemodynamic and histological studies which show that in diabetes there is an intrinsic abnormality of myocardium.

I would like to thank Drs R F Fletcher and B A Leatherdale for permission to report patients under their care, and ICI Limited for financial assistance.

\section{References}

1 Shapiro LM, Howat AP, Calter MM. Left ventricular function in diabetes mellitus. I. Methodology, and prevalence and spectrum of abnormalities. Br Heart $\mathcal{F} 1981$; 45: 122-8.

2 Shapiro LM, Leatherdale BA, Mackinnon J, Fletcher RF. Left ventricular function in diabetes mellitus. II. Relation between clinical features and left ventricular function. Br Heart $\mathcal{f}$ 1981; 45: 129-32.

3 Ahmed SS, Jaferi GA, Narang RM, Regan TJ. Preclinical abnormality of left ventricular function in diabetes mellitus. Am Heart $\mathcal{F}$ 1975; 89: 153-8.

4 Seneviratne BIB. Diabetic cardiomyopathy: the preclinical phase. $\mathrm{Br}$ Med $\mathcal{F}$ 1977; i: $1444-6$.

5 Shapiro LM, Leatherdale BA, Coyne ME, Fletcher RF, Mackinnon J. Prospective study of heart disease in untreated maturity onset diabetics. Br Heart $\mathcal{F}$ 1980; 44: 342-8.
6 Sanderson JE, Brown DJ, Rivellese A, Kohner E. D) Diabetic cardiomyopathy? An echocardiographic study of young diabetics. $\mathrm{Br} \mathrm{Med} \mathrm{F} \mathrm{1978;} \mathrm{i:} \mathrm{404-7.}$

7 Gibson DG, Brown D. Measurement of instantaneous $\overline{\bar{s}}$ left ventricular dimension and filling rate in man, using echocardiography. Br Heart $\mathcal{F}$ 1973; 35: 1141-9.

8 Traill TA, Gibson DG, Brown DJ. Study of left ven- $\overline{\bar{c}}$ tricular wall thickness and dimension changes using echocardiography. Br Heart f 1978; 40: 162-9.

9 Upton MT, Gibson DG, Brown DJ. Echocardiographic assessment of abnormal left ventricular relaxation in $\vec{\theta}$ man. Br Heart f 1976; 38: 1001-9.

10 Chen W, Gibson D. Relation of isovolumic relaxation to left ventricular wall movement in man. Br Heart $\mathcal{F} 1979$; 42: $51-6$.

11 Gibson DG, Traill TA, Hall RJC, Brown DJ. Echocardiographic features of secondary left ventricular hyper- -7 trophy. Br Heart f 1979; 41: 54-9.

12 Ledet T. Diabetic cardiopathy. Quantitative histological $\vec{\omega}$ studies of the heart from young juvenile diabetics. Acta Pathol Microbiol Scand [A] 1976; 84: 421-8.

13 Regan TJ, Haider B, Lyon MM. Altered ventricularfunction and metabolism in diabetes mellitus. In: $\bar{z}$ Zoneraich S, ed. Diabetes and the heart. Springfield, Illinois: Charles C Thomas, 1978: 123-36.

14 Factor SM, Okun EM, Minase T. Capillary microaneurysms in the human diabetic heart. $N$ Engl F Med 1980; 302: 384-8.

15 Hamby RI, Zoneraich S, Sherman L. Diabetic cardiomyopathy. $\mathcal{F} A M A$ 1974; 229: 1749-54.

16 Traill TA, Gibson DG. Left ventricular relaxation ando filling: study by echocardiography. In: Yu PN, Goodwin JF, eds. Progress in cardiology. vol 8. Philadelphia: Lea \& Febiger, 1979: 39-72.

Requests for reprints to Dr L M Shapiro, Royal Postgraduate Medical School, Hammersmith Hospital, Du Cane Road, London W12 0HS. 